\title{
Phenological response of plants to temperature varies at the same latitude: case study of dog violet and horse chestnut in England and Poland
}

\author{
Piotr Tryjanowski ${ }^{1, *}$, Marek Panek $^{2}$, Tim Sparks $^{3}$ \\ ${ }^{1}$ Department of Behavioural Ecology, Adam Mickiewicz University, Umultowska 89, 61-614 Poznan, Poland \\ ${ }^{2}$ Polish Hunting Association, Research Station, Sokolnicza 12, 64-020 Czempin, Poland \\ ${ }^{3}$ NERC Centre for Ecology and Hydrology, Monks Wood, Abbots Ripton, Huntingdon, Cambridgeshire PE28 2LS, UK
}

\begin{abstract}
We analysed phenological observations of first flowering of early dog violet Viola reichenbachiana and horse chestnut Aesculus hippocastanum at similar latitudes (and hence photoperiod) in the UK and Poland during the 26 years 1970-1995. Temperatures in Poland were significantly colder than in the UK for February and March and significantly warmer in May. Mean first flowering dates of both species were not significantly different between the 2 countries. However, records in the UK were significantly more variable. Both species in both locations showed significant temperature responsiveness although plants in the UK were more responsive than those in Poland. We conclude that locally adapted species may differ in their projected change under future climate warming.
\end{abstract}

KEY WORDS: Flowering · Temperature response rate · Phenology · Photoperiod · Climate change · Viola reichenbachiana A Aesculus hippocastanum

\section{INTRODUCTION}

Seasonally advanced leafing and flowering has been reported from across Europe and North America (e.g. Menzel \& Fabian 1999, Abu-Asab et al. 2001, Fitter \& Fitter 2002). This can affect changes in the environment with consequences for animals (Post \& Stenseth 1999, Fitter \& Fitter 2002). The onset of spring and summer events, and consequently the length of the growing season, is very sensitive to climate and weather, as nearly all phenophases correlate with temperatures in the preceding 1 to 3 months (Sparks et al. 2000, Sparks \& Menzel 2002, Menzel 2003).

A growing number of studies where observations include the recent decade of globally warm years have reported phenological advance (reviews in: Root et al.
2003, Schwartz 2003, Badeck et al. 2004, Walther et al. 2002). However, change in phenology, even in the same species, is not uniform across its distributional range. Is this solely due to differential warming across the range, or could differences in latitude (and hence in photoperiod) also be important?

In this paper we compare the flowering phenology of 1 woodland herb and 1 tree species between the Wielkopolska region of western Poland (one of the few plant phenological records for Poland and where only the 2 species were recorded) and Oxfordshire in central England; both locations are at similar latitudes and hence have similar photoperiod patterns. In particular we were interested in whether the temperature response of these species differs at similar latitudes with very different climates. 


\section{MATERIALS AND METHODS}

\subsection{Study areas and data sources}

Observations on the first flowering dates (FFD) in 1970-1995 of 2 plant species, the native woodland herb early dog violet Viola reichenbachiana and the ornamental tree (planted in Europe since Roman times) horse chestnut Aesculus hippocastanum, were recorded in a park of deciduous forest in Borowo, Wielkopolska region, western Poland $\left(52^{\circ} 07^{\prime} \mathrm{N}\right.$, $\left.16^{\circ} 46^{\prime} \mathrm{E}\right)$. The park is surrounded by farmland. Comparable records (some $1200 \mathrm{~km}$ to the west) collected by R.S.R. Fitter in and around Chinnor, Oxfordshire, UK $\left(51^{\circ} 42^{\prime} \mathrm{N}, 0^{\circ} 42^{\prime} \mathrm{W}\right)$ in the period 1954-2000 were available (Fitter \& Fitter, 2002), from which records for 1970-1995 were extracted. An extremely early record of 15 January 1975 for early dog violet was omitted from further analysis as it was far removed from the remaining data (standardized residual -3.77 ). Three horse chestnut and one early dog violet records were missing from the UK data. The similar latitudes, a difference of only $25^{\prime}$ or about $46 \mathrm{~km}$, mean that both sites will have a very similar photoperiod.

Monthly air temperature data for the period 1970-1995 were obtained from the meteorological records of the Borowo Plant Breeding Station, located in the same park where flowering data were collected. For the UK, mean monthly central England temperatures, derived from several weather stations, were obtained from the UK Met Office website (www.met office.gov.uk/).

To assess the potential climate influence on a larger scale we used the mean North Atlantic Oscillation (NAO) index for the months of December to March for the same years (www.cru.uea.ac.uk/ timo/projpages/ nao_update.htm). The NAO is a natural large-scale atmospheric fluctuation between subtropical and subpolar North Atlantic regions. It affects climatic and ecological dynamics over a large area, including Europe and Africa (Ottersen et al. 2001, Menzel 2003, Menzel et al. 2005b). linearly (Menzel et al. 2005a). Trends over time were determined by linear regression of response variables against year, and relationships with temperature by correlation and regression analyses.

\section{RESULTS}

\subsection{Trends in first flowering dates}

Mean flowering dates in the UK and Poland were not significantly different for either early dog violet (paired $t$-test, $t_{24}=-0.89, \mathrm{p}=0.38$ ) or horse chestnut (paired $t$-test, $\left.t_{22}=-1.35, \mathrm{p}=0.19\right)$. The greater variability in dates of the UK plants is evident in Table 1 and Fig. 1 and was confirmed by variance ratio tests (early dog violet $F_{24,25}=2.53, \mathrm{p}=0.026$; horse chestnut $F_{22,25}=4.68$, $\mathrm{p}<0.001)$. First flowering dates of early dog violet were correlated between both countries $\left(\mathrm{r}_{24}=0.62, \mathrm{p}=0.001\right)$, as were those of horse chestnut $\left(\mathrm{r}_{22}=0.44, \mathrm{p}=0.038\right)$. Early dog violet and horse chestnut first flowering dates were correlated with each other in both countries (UK: $r_{21}=0.65$, Poland: $r_{25}=0.60$, both $p=0.001$ ).

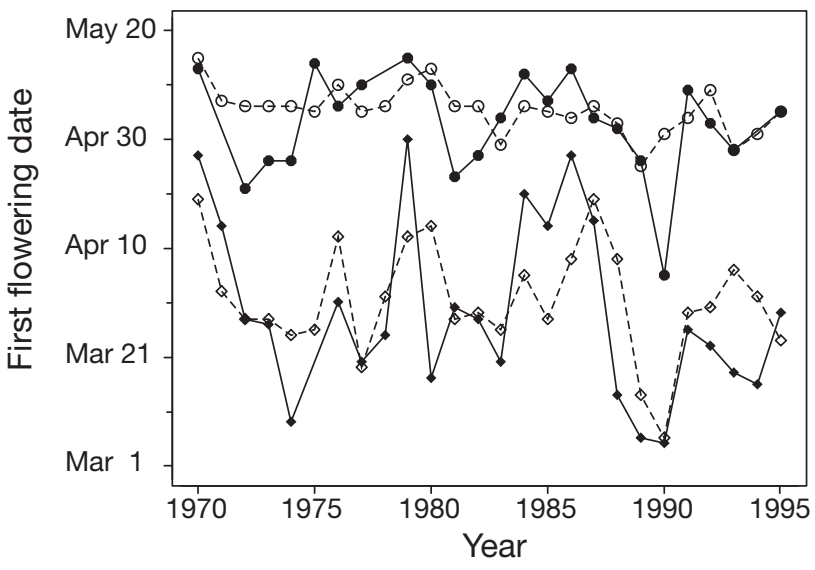

Fig. 1. Viola reichenbachiana and Aesculus hippocastanum. First flowering dates of early dog violet $(\bullet)$ and horse chestnut $(\bullet)$ in the UK (solid symbols, solid lines) and Poland (open symbols, broken lines)

\subsection{Statistical analysis}

Means of first flowering dates were compared using paired $t$-test and variances were compared using variance ratio tests. Previous studies have shown that for the onset of plant activity in spring the temperatures of the preceding months are decisive (Sparks et al. 2000, Menzel 2003, Menzel et al. 2005a,b) and plants respond to this factor approximately
Table 1. Viola reichenbachiana and Aesculus hippocastanum. Information on the first flowering of early dog violet (EDV) and horse chestnut (HC) in Chinnor (UK) and Borowo (Poland), 1970-1995. $\mathrm{n}=$ number of years, SD = standard deviation

\begin{tabular}{|lrlrlll|}
\hline Site/species & $\mathrm{n}$ & Mean & $\mathrm{SD}$ & Median & Earliest & Latest \\
\hline UK & & & & & & \\
EDV & 25 & 29 March & 16.3 & 27 March & 5 March & 30 April \\
HC & 23 & 3 May & 9.4 & 4 May & 5 April & 15 May \\
Poland & & & & & & \\
EDV & 26 & 31 March & 10.3 & 29 March & 6 March & 19 April \\
HC & 26 & 5 May & 4.3 & 6 May & 25 April & 15 May \\
\hline
\end{tabular}


Table 2. Viola reichenbachiana and Aesculus hippocastanum. Trends (per annum changes) in first flowering dates of early dog violet (EDV) and horse chestnut (HC) in the UK and Poland, in mean monthly temperatures in both locations and in winter NAO, 1970-1995

\begin{tabular}{|llll|}
\hline & \multicolumn{3}{c}{ Regression } \\
\cline { 2 - 3 } & Coefficient & SE & $\mathrm{p}$ \\
\hline Flowering dates & & & \\
UK: EDV & -0.63 & 0.42 & 0.148 \\
UK: HC & -0.19 & 0.28 & 0.491 \\
Poland: EDV & -0.26 & 0.27 & 0.340 \\
Poland: HC & -0.31 & 0.10 & 0.004 \\
Temperature (UK) & & & \\
February & 0.017 & 0.049 & 0.730 \\
March & 0.078 & 0.031 & 0.021 \\
April & 0.042 & 0.025 & 0.105 \\
May & 0.019 & 0.026 & 0.480 \\
Temperature (PL) & & & \\
February & 0.017 & 0.085 & 0.841 \\
March & 0.049 & 0.056 & 0.388 \\
April & 0.091 & 0.023 & 0.001 \\
May & 0.051 & 0.041 & 0.223 \\
Winter NAO & 0.078 & 0.025 & 0.004 \\
\hline
\end{tabular}

Regressions against year revealed that whilst all trends were negative, i.e. towards earlier flowering, only that for horse chestnut in Poland was significant (Table 2).

\subsection{Temperatures during the study period}

Trends in temperatures between February and March in 1970-1995 all produced positive coefficients but only that for March in the UK and April in Poland were statistically significant (Table 2). The winter NAO also increased significantly. UK temperatures were significantly warmer than Poland in February and March but by May the situation was reversed with UK temperatures significantly cooler than Poland (Table 3). In all of the examined months, except April, Polish temperatures were significantly more variable than UK temperatures (Table 3 ).
Table 4. Correlations between first flowering dates of early dog violet (EDV) and horse chestnut (HC) and mean monthly temperatures and the winter NAO index. Months post mean flowering date not included. Correlations in bold are statistically significant $(\mathrm{p}<0.05)$

\begin{tabular}{|lccccc|}
\hline \multirow{2}{*}{ Site/species } & \multicolumn{6}{c|}{ Correlation (r) } & with temperature & Winter \\
& Feb & Mar & Apr & May & NAO \\
\hline UK: EDV & $\mathbf{- 0 . 6 5}$ & $\mathbf{- 0 . 7 3}$ & & & $\mathbf{- 0 . 5 9}$ \\
UK: HC & $\mathbf{- 0 . 5 4}$ & $\mathbf{- 0 . 6 6}$ & -0.12 & -0.36 & $\mathbf{- 0 . 5 2}$ \\
Poland: EDV & $\mathbf{- 0 . 5 2}$ & $\mathbf{- 0 . 8 4}$ & & & $\mathbf{- 0 . 5 2}$ \\
Poland: HC & -0.19 & $\mathbf{- 0 . 5 0}$ & $\mathbf{- 0 . 4 6}$ & $\mathbf{- 0 . 6 0}$ & $\mathbf{- 0 . 6 1}$ \\
\hline
\end{tabular}

\subsection{Influence of temperature and NAO on FFD}

Correlations between first flowering dates and temperature for the February-May period and the winter NAO index are given in Table 4. Early dog violet flowering in both countries was significantly negatively correlated with February and March temperatures. UK horse chestnut flowering dates were significantly negatively correlated with February and March temperatures, whilst horse chestnut in Poland was significantly negatively correlated with March, April and May temperatures. All 4 flowering series were significantly negatively correlated with winter NAO index (Table 4).

Regressions of early dog violet against February and March temperature and horse chestnut against February-May temperatures are summarised in Table 5. All series produced significant relationships with temperature and in both countries the temperature response in early dog violet was stronger than that for horse chestnut. Total responses in the UK were greater than those in Poland, i.e. a $1^{\circ} \mathrm{C}$ increase in temperature was associated with a greater advance of flowering in the UK. In a comparison of the temperature responses of the 2 countries using temperature data averaged over months (Fig. 2) the temperature response of early dog violet in the UK is significantly greater than that in Poland (test of equality of slopes $F_{1,47}=24.74, \mathrm{p}<0.001$ ), as is that for horse chestnut $\left(F_{1,45}=8.85, \mathrm{p}=0.005\right)$.
Table 3. Mean monthly temperatures $\left({ }^{\circ} \mathrm{C}\right)$ in the UK and Poland together with their standard deviation (SD), paired $t$-test comparing means, and variance ratio test to compare variances

\begin{tabular}{|lrrrrrrrrr|}
\hline \multirow{2}{*}{ Month } & \multicolumn{3}{c}{ Temperature $\left({ }^{\circ} \mathrm{C}\right)$} & \multicolumn{2}{c}{$t$-test } & \multicolumn{3}{c|}{ Variance } \\
& \multicolumn{2}{c}{ UK } & \multicolumn{2}{c}{$\begin{array}{c}\text { Poland } \\
\text { ratio test }\end{array}$} \\
& Mean & SD & Mean & SD & \multicolumn{1}{c}{$t_{25}$} & $\mathrm{p}$ & \multicolumn{2}{c}{$F_{25,25}$} & $\mathrm{p}$ \\
\hline February & 3.92 & 1.85 & -0.40 & 3.19 & 13.24 & $<0.001$ & 2.98 & 0.008 \\
March & 6.00 & 1.32 & 3.52 & 2.13 & 9.58 & $<0.001$ & 2.60 & 0.020 \\
April & 7.94 & 0.99 & 7.55 & 1.12 & 1.48 & 0.151 & 1.27 & 0.549 \\
May & 11.30 & 0.99 & 13.27 & 1.59 & -5.83 & $<0.001$ & 2.61 & 0.020 \\
\hline
\end{tabular}

\section{DISCUSSION AND CONCLUSIONS}

This study revealed strong correlations between first flowering dates and both temperature and winter NAO for both early dog violet and horse chestnut. In common with other studies (Sparks \& Carey 1995, Fitter \& Fitter 2002, Menzel et al. 2005a), the earlier species, early dog violet, was more 
Table 5. Summary of regressions of first flowering dates of early dog violet (EDV) on February and March temperatures and of horse chestnut (HC) on February-May temperatures. Regression coefficients in bold are statistically significant ( $p<0.05$ ). The total figure is the sum of the coefficients and estimates the combined effects of a $1^{\circ} \mathrm{C}$ increase in temperature in the analysed months on flowering date

\begin{tabular}{|c|c|c|c|c|c|c|c|c|}
\hline \multirow[t]{2}{*}{ Site/species } & \multicolumn{4}{|c|}{ Regression coefficients (days $/{ }^{\circ} \mathrm{C}$ ) } & \multirow[t]{2}{*}{ Total } & \multirow[t]{2}{*}{$\mathrm{R}_{2}$} & \multirow[t]{2}{*}{$F$} & \multirow[t]{2}{*}{$\mathrm{p}$} \\
\hline & Feb & Mar & Apr & May & & & & \\
\hline UK: EDV & -4.2 & -7.3 & & & -11.5 & 75.3 & $F_{2,22}=33.52$ & $<0.001$ \\
\hline UK: HC & -1.5 & -3.9 & -0.5 & -0.4 & -6.3 & 55.3 & $F_{4,18}=5.58$ & 0.004 \\
\hline Poland: EDV & -1.0 & -3.6 & & & -4.6 & 79.5 & $F_{2,23}=44.57$ & $<0.001$ \\
\hline Poland: HC & -0.1 & -0.9 & -2.2 & -0.6 & -3.8 & 68.7 & $F_{4,21}=11.54$ & $<0.001$ \\
\hline
\end{tabular}

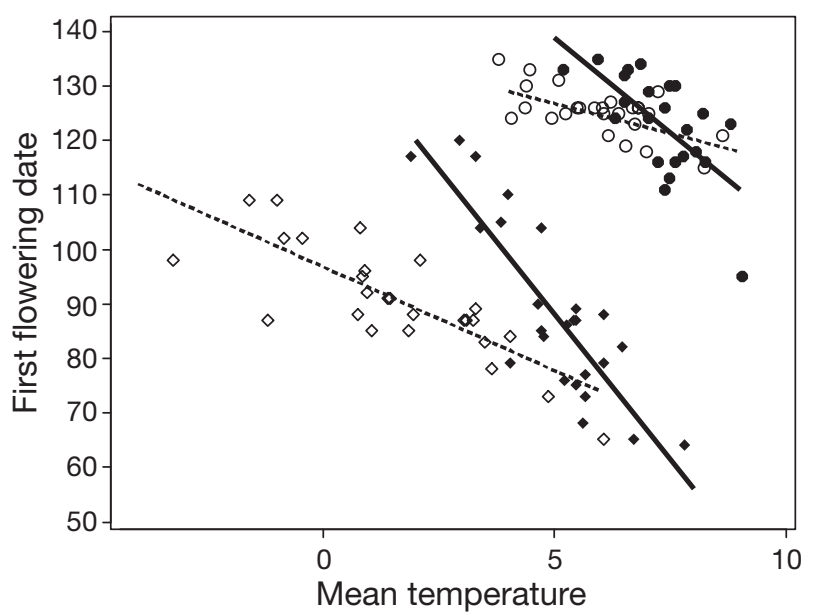

Fig. 2. Viola reichenbachiana and Aesculus hippocastanum. First flowering dates (days after December 31) of early dog violet $(\bullet)$ regressed against mean February-March temperature and horse chestnut $(\bullet)$ regressed against mean February-May temperature in the UK (solid symbols, solid lines) and Poland (open symbols, broken lines)

temperature responsive than the later species, horse chestnut. Species in the 2 locations had similar mean first flowering dates despite the colder early spring temperatures in Poland. In the UK, phenological observations were more variable but temperatures less variable than in Poland. The UK records displayed much stronger temperature responsiveness than in Poland.

There are good reasons why day length and photoperiod might prohibit a too early start of the growing season, even in very warm springs (Badeck et al. 2004). Since the locations were at very similar latitudes they would experience a very similar photoperiod. Therefore, we assume that differences in day-length cannot account for differences between species at the 2 locations. These results suggest that species may be locally adapted to their own environment, even for a species alien to both locations i.e. horse chestnut. Polish temperatures in early spring are more variable and hence less predictable. Early flowering individuals of a species may be at a much greater risk (of frost damage) than in the UK. Sparks et al. (2000) suggested that temperature response may be sigmoidal, steepest in the mid range of phenological dates. However, this cannot explain the differences in responsiveness reported here since mean dates were broadly similar between the 2 countries.

Another potential issue is that temperatures below a certain threshold (e.g. $5^{\circ} \mathrm{C}$, depending on the species) may not be effective as forcing temperature; this can explain differences between species and might also explain a reduced response rate. However, different thresholds between the 2 countries would again point to local adaptation.

Although we have only looked at 2 species in 2 locations there is strong evidence that identical species have a different response to temperature, even at the same latitude. This may point to local adaptation to climate and suggest that response to future climate warming will also vary at the same latitude. This may further suggest that not all of the differential phenological response so far reported is attributable to differential warming. Could we also expect greater adaptation in native species than non-native ones? Obviously such broad statements need confirmation from larger data sets. Additionally, there are opportunities to acquirer further data from the International Phenological Gardens (Chmielewski \& Rötzer 2001, Menzel et al. 2005b) where genetically identical trees are grown across Europe.

Acknowledgements. We thank A. Wróbel and H. Woś for help in collecting Polish field data, J. Karg for assistance with obtaining Polish temperature data, A. Fitter for permission to use the UK data and the late R. S. R. Fitter for his dedication to phenology.

\section{LITERATURE CITED}

Abu-Asab MS, Peterson PM, Shetler SG, Orli SS (2001) Earlier plant flowering in spring as a response to global warming in the Washington, DC, area. Biodivers Conserv 10:597-612

Badeck FW, Bondeau A, Böttcher K, Doktor D, Lucht W, Schaber J, Sitch S (2004) Responses of spring phenology to climate change. New Phytol 162:295-309 
Chmielewski FM, Rötzer T (2001) Response of phenology to climate change across Europe. Agric Meteorol 108: 101-112

Fitter AH, Fitter RSR (2002) Rapid changes in flowering time in British plants. Science 296:1689-1691

Menzel A (2003) Plant phenological anomalies in Germany and their relation to air temperature and NAO. Clim Change 57:243-263

Menzel A, Fabian P (1999) Growing season extended in Europe. Nature 397:43-44

Menzel A, Estrella N, Testka A (2005a) Temperature response rates from long-term phenological records. Clim Res 30: 21-28

Menzel A, Sparks TH, Estrella N, Eckhardt S (2005b) 'SSW to NNE' - North Atlantic Oscillation affects the progress of seasons across Europe. Global Change Biol 11:909-918

Ottersen G, Planque B, Belgrano A, Post E, Reid PC, Stenseth NC (2001) Ecological effects of the North Atlantic Oscillation. Oecologia 128:1-14

Editorial responsibility: Mauricio Lima, Santiago, Chile
Post E, Stenseth NC (1999) Climatic variability, plant phenology, and northern ungulates. Ecology 80:1322-1339

Root TL, Price JT, Hall KR, Schneider SH, Rosenzweig C, Pounds JA (2003) Fingerprints of global warming on wild animals and plants. Nature 421:57-60

Schwartz MD (ed) (2003) Phenology: an integrative environmental science. Kluwer Academic Publishers, Dordrecht

Sparks TH, Carey PD (1995) The response of species to climate over 2 centuries: an analysis of the Marsham phonological record, 1736-1947. J Ecol 83:321-329

Sparks TH, Menzel A (2002) Observed changes in seasons: an overview. Int J Climatol 22:1715-1725

Sparks TH, Jeffree EP, Jeffree CE (2000) An examination on the relationship between flowering times and temperature at the national scale using long-term phenological records from the UK. Int J Biometeorol 44:82-87

Walther GR, Post E, Convey P, Menzel A and 5 others (2002) Ecological responses to recent climate change. Nature 416:389-395

Submitted: March 15, 2006; Accepted: May 30, 2006

Proofs received from author(s): July 17, 2006 